\title{
EI ASRS v.1.1. como instrumento de cribado del trastorno por déficit de atención e hiperactividad en adultos tratados por conductas adictivas: propiedades psicométricas y prevalencia estimada
}

\author{
Eduardo J. Pedrero Pérez*; Carmen Puerta García** \\ *Psicólogo ** Médico \\ Enviar correspondencia a: \\ Eduardo J. Pedrero. Centro de Atención a Drogodependencias \\ CAD-4-San Blas. Instituto de Adicciones. Ayuntamiento de Madrid. C/ Alcalá, 527. 28027 MADRID. Tfno: 609587233. Fax: 917434775 \\ e-mail: ejpedrero@yahoo.es
}

Recibido: Febrero de 2007

Aceptado: Septiembre de 2007

\section{RESUMEN}

EI ASRS v.1.1. es un instrumento breve autoaplicado para el cribado inicial de sujetos con síntomas actuales del trastorno por déficit de atención e hiperactividad (TDAH) propuesto por la OMS. Efectuamos un estudio descriptivo transversal del instrumento y de los resultados de su aplicación a una muestra de 280 sujetos en tratamiento por abuso/dependencia de sustancias. Se administran simultáneamente en las fases iniciales del tratamiento la versión abreviada del ASRS v.1.1. y el MCMI-Il a todos ellos, y la Wender Utah Rating Scale (WURS), el ADHD-Rating Scale-IV y la versión completa del ASRS v.1.1. a diversas submuestras para efectuar pruebas de validez. Se efectúan también entrevistas diagnósticas. Se estudian las propiedades psicométricas y estructura factorial del ASRS v.1.1. Se observan adecuadas cifras de validez convergente, sensibilidad, especificidad y capacidad diagnóstica para la versión de 6 ítems del ASRS v.1.1., si bien 4 de los 6 ítems no discriminan entre otros trastornos del Eje I y II estimados mediante el MCMI-II y entrevistas diagnósticas. Aplicados los criterios DSM-IV-TR, la prevalencia estimada de TDAH en la muestra de adictos es del 8,2\%. Se discuten los resultados, admitiendo al ASRS v.1.1. como instrumento eficaz para el cribado inicial, aunque evidenciando que lo que sus ítems miden es una dimensión inespecífica de compulsividad/impulsividad, común a muchos trastornos de los dos primeros ejes. Se cuestiona también la inespecificidad de los criterios DSM, la confusión que generan entre los conceptos de síntoma, signo y rasgo, y su impacto en los resultados de los estudios, la aplicación general del criterio $A$, pero la general omisión de los criterios B, C, D y E, y las diferencias entre las muestras de diversos estudios, tanto en severidad como en los criterios de selección, y la artefactual elevación de cifras de prevalencia derivadas de estas cuestiones.

Palabras clave: trastorno por déficit de atención e hiperactividad, TDAH, ASRS v.1.1., MCMI-II, adicción, trastorno por abuso o dependencia de sustancias, evaluación, diagnóstico, prevalencia.

\section{ABSTRACT}

ASRS v.1.1. is a self-applied brief instrument for the screening of individuals presenting symptoms of attentiondeficit/hyperactivity disorder (ADHD), and proposed by the WHO. The purpose of the present work was to test the instrument and examine the results of its application to a sample of 280 individuals in treatment for substance-related disorders (crosssectional descriptive study). We administered simultaneously in the initial phases of treatment the ASRS v.1.1. (short form) and the MCMI-II to the full sample and the Wender Utah Rating Scale (WURS), ADHD-Rating Scale-IV and ASRS v.1.1. (complete form) to various sub-samples. Diagnostic interviews were also carried out and the psychometric properties and factorial structure of ASRS v.1.1. were explored. Good convergent validity, sensitivity, specificity and diagnostic capability were obtained for the six-item version of ASRS v.1.1., even though 4 out of 6 items did not discriminate between Axis I and II disorders assessed through the MCMIII and diagnostic interviews. According to DSM-IV-TR criteria the estimated prevalence of ADHD in the sample of addicts was $8.2 \%$. ASRS v.1.1. is criticized as a specific instrument for ADHD detection, since most of its items appear to measure a non-specific dimension of compulsiveness/impulsiveness, common to Axis-I and Axis-II disorders. Other criticisms made in the discussion concern the lack of specificity of DSM criteria and the confusion they generate among the concepts of symptom, sign and trait (including the impact on study results), the general use of the A criterion but the omission of the $B, C, D$ and $E$ criteria of the DSM category, differences in samples (with regard to both severity and selection criteria), and the artifactual increases in prevalence found in many studies.

Key words: Attention-deficit/hyperactivity disorder ADHD, ASRS v.1.1., MCMI-II, addiction, substance-related disorders, assessment, diagnosis, prevalence. 


\section{INTRODUCCIÓN}

E xiste en la actualidad un creciente interés en la investigación del trastorno por déficit de atención e hiperactividad (en adelante TDAH) en población adulta. Considerado hasta hace un par de décadas una afectación infantil, existen evidencias clínicas de que los déficits no desaparecen con la maduración, acaso se modifican, y provocan importantes dificultades en la adaptación de las personas que la padecen. Los adultos con síntomas de TDAH muestran un peor ajuste en su vida familiar (Eakin, Minde, Hechtman, Ochs, Krane, Bouffard et al., 2004) y laboral (Kessler, Adler, Ames, Barkley, Russell, Birnbaum et al., 2005). No parecen existir diferencias de género en la expresión de la sintomatología y la psicopatología concomitante (Biederman, Faraone, Monuteaux, Bober y Cadogen, 2004).

Para cumplir los criterios de diagnóstico de DSMIV , un adulto debe manifestar un patrón crónico de rasgos de inatención y/o rasgos de impulsividad/hiperactividad que no sean debidos a otra condición. Los síntomas deben provocar "un deterioro clínicamente significativo" en al menos dos áreas de funcionamiento (social, académico u ocupacional) y haber estado presentes desde los 7 años o con anterioridad. Los individuos que exhiben características prominentes, pero no cumplen los criterios por completo, pueden ser diagnosticados como TDAH no especificado (APA, 2002). Se han propuesto también otros criterios para su estudio, de cara a la modificación de la categoría en futuras ediciones clasificatorias; los criterios de Utah incluyen preceptos más amplios, que requieren la existencia de los síntomas DSM-IV desde la infancia, además de dos criterios específicos (hiperactividad e inatención) y al menos uno de los siguientes: problemas de conducta en la escuela, impulsividad, hiperexcitabilidad y temperamento explosivo (Wender, Wolf y Wasserstein, 2001).

Está en cuestión en el momento actual, de cara a su inclusión en futuras clasificaciones, la validez de la categoría diagnóstica de TDAH en el adulto. Para que una categoría psicopatológica sea válida se considera generalmente que debe derivarse de un patrón consistente de datos, con criterios estándar de validación que incluyan historia familiar, respuesta al tratamiento, estudios de laboratorio, curso clínico y resultados. Los síntomas del TDAH en adultos son similares a los que se presentan en la infancia, si bien la intensidad de varios síntomas puede cambiar con la edad. La hiperactividad puede adaptarse con el desarrollo, pero la impulsividad, la distractibilidad y la fatigabilidad pueden convertirse en obstáculos para el normal desempeño en la vida cotidiana. Estas alteraciones parecen mostrarse en diferentes dominios que incluyen el mal funcionamiento académico, problemas ocupacionales y dificultades relacionales. Los adultos con TDAH tienen más posibilidades de padecer trastornos de ansiedad, del estado de ánimo, personalidad antisocial y abuso de sustancias. La validez del diagnóstico parece avalada también por estudios de familia que encuentran una elevada heredabilidad del trastorno. La hipoactividad domapinérgica prefrontal ha sido demostrada en niños y adultos con TDAH, con un perfil de déficits neuropsicológicos similar, con déficits en la vigilancia, inhibición motora, funciones ejecutivas, aprendizaje verbal y memoria de trabajo. La respuesta a los tratamientos de estimulantes es similar también en niños y adultos. Todos estos hallazgos parecen apoyar la validez del diagnóstico de TDAH en el adulto (Weisler, 2004; Faraone y Biederman, 2005).

Un informe reciente del US National Comorbidity Survey Replication encuentra una prevalencia del $4,4 \%$ en adultos, utilizando criterios diagnósticos conservadores (Kessler, Adler, Barkley, Biederman, Conners, Delmer et al., 2006).

Estudios econométricos han mostrado la necesidad de establecer diagnósticos y tratamientos adecuados para los adultos afectados por el TDAH, dado que éstos pacientes presentan costes muy elevados en la medida en que es mucho más probable el diagnóstico de asma, ansiedad, trastorno bipolar, depresión, trastorno por abuso de sustancias, trastorno antisocial de la personalidad $u$ otros, lo que supone mayor gasto en tratamientos ambulatorios u hospitalarios, prescripción de medicamentos o costes laborales por bajas médicas (Secnik, Swensen y Lage, 2005). De especial interés se revela la detección del trastorno en personas que son tratadas por abuso o dependencia de sustancias; es conocida la tendencia de las personas que padecen el TDAH en la infancia a iniciar y mantener conductas adictivas (Biederman, Wilens, Mick, Spencer y Faraone, 1999), habiéndose formulado diversas hipótesis para dar cuenta de esta asociación de trastornos (Pedrero, Puerta, Olivar, Lagares y PérezLópez, 2004). Es previsible que si existe un porcentaje significativo de sujetos que, padeciendo un TDAH, inician un patrón abusivo de consumo de sustancias, a la inversa, entre quienes están en tratamiento por consumo de sustancias debamos encontrar porcentajes significativos de individuos con sintomatología de TDAH. De ser así, quizá el abordaje farmacológico y psicoterapéutico de esta población pudiera beneficiarse de intervenciones más simples y específicas, que han demostrado su utilidad frente al TDAH (Comings, Chen, Blum, Mengucci, Blum y Meshkin, 2005).

Se estima que entre un 20 y un $30 \%$ de las personas con trastorno por abuso de sustancias presentan sintomatología de TDAH, mientras que entre un 20 y 
$40 \%$ de los sujetos adultos con TDAH presentan en su historial algún trastorno por abuso de sustancias (Schubiner, 2005), aunque parece existir una vulnerabilidad selectiva a drogas como la nicotina y la cocaína (Davids y Gastpar, 2003). Un estudio suizo explora una muestra de 100 pacientes dependientes de opiáceos (Modestin, Matutat y Würmle, 2001) encontrando que el $11 \%$ cumplen los criterios DSM-IV para TDAH en el adulto, aunque sólo un $4 \%$ sin problemas de conducta asociados. Los autores concluyen que, al menos en los consumidores de heroína, la existencia de síntomas de TDAH no parece asociarse significativamente con trastornos adictivos, salvo que concurran conducta agresiva u otros problemas de conducta, siendo éstos y no los problemas de inatención o hiperactividad los precursores del abuso de sustancias.

En Holanda existen en marcha programas que detectan y atienden el TDAH en población adicta. Un estudio preliminar sobre 928 pacientes encontró que el $22,3 \%$ puntuaban positivamente en pruebas de screening, siendo finalmente el $7 \%$ diagnosticados de TDAH, si bien estos resultados estuvieron mediatizados por una importante mortalidad experimental (Goossensen, Van de Glind, Carpentier, Wijsen, Van Duin y Kooij, 2006).

Recientemente se ha desarrollado por la Organización Mundial de la Salud un instrumento de screening para la detección del TDAH en adultos. El ADHD Self-Report Scale (ASRS v.1.1) es un autoinforme que consta de 18 ítems, siendo utilizados los 6 primeros como escala de cribado. Los estudios preliminares sugieren que la versión corta mejora las propiedades de la escala completa en cuanto a sensibilidad $(68,7 \%$ vs $56,3 \%)$, especificidad $(99,5 \%$ vs $98,3 \%)$ y exactitud clasificatoria (97,9\% vs 96,2\%) (Kessler, Adler L, Ames M, Demler, O., Faraone, S., Hiripi et al., 2005). Apenas hay disponibles aún estudios desarrollados con este instrumento, aunque alguno de ellos aporta evidencia sobre su validez externa en relación a genes candidatos a formar parte del sustrato genético del TDAH (Reuter, Kirsch y Hennig, 2005).

El objetivo del presente trabajo se centra en explorar el ASRS v1.1 utilizándolo en una muestra de adictos que inician tratamiento, para conocer sus propiedades psicométricas, su validez convergente con otros cuestionarios enfocados a la detección de TDAH y su validez discriminante con otros instrumentos de medida psicopatológica, como el MCMI-II. A partir de los resultados, y mediante la combinación de métodos diagnósticos, se estudiará la prevalencia del trastorno en la muestra estudiada.

\section{MÉTODO}

\section{Muestra}

Se obtiene una muestra de 280 sujetos, 218 varones y 62 mujeres, que inician tratamiento por problemas relacionados con el consumo de sustancias, y reciben como diagnóstico principal el de abuso o dependencia de heroína $(19,6 \%)$, cocaína $(45,4 \%)$, alcohol $(30,0 \%)$ o cannabis (5\%). La media de edad es, respectivamente, de 38,3 (DT = 7,1), 31,5 (DT = $6,8), 40,6(D T=9,7)$ y 29,0 (DT $=10,2$ ) años. El tiempo medio de consumo de la sustancia es de 14,6 (DT $=8,7)$ años para los de heroína, 7,1 (DT $0=6,2$ ) para los de cocaína, 21,6 (DT $=12,8$ ) para los de alcohol y $7,2(\mathrm{DT}=7,1)$ para los de cannabis.

\section{Instrumentos}

El Adult ADHD Self-Report Scale Version 1.1 (ASRS v.1.1) es un cuestionario de 18 ítems que mide síntomas actuales de TDAH en población adulta, desarrollado por el grupo de trabajo de la Organización Mundial de la Salud conjuntamente con la versión de la WHO Composite International Diagnostic Interview (WMH-CIDI). Se puntúan en una escala de 5 opciones (nunca, raramente, a veces, con frecuencia y muy frecuentemente) y se estima para cada ítem una puntuación de corte o criterial, a partir de la cual el ítem es considerado positivo (puntuación 1) y por debajo del cual es considerado negativo (puntuación 0). Este punto de corte se sitúa en el tercer valor ("Algunas veces") para los ítems 1, 2, 3, 9, 12, 16 y 18, y en el cuarto valor ("Con frecuencia") para el resto. Las puntuaciones también pueden ser tratadas como una escala continua entre el 0 ("Nunca") y el 4 ("Muy frecuentemente").

Los 6 primeros ítems conforman la versión de cribado (ASRS Screening; figura 1) para la detección rápida de síntomas sugestivos de TDAH en adultos. Los ítems interrogan sobre la presencia de síntomas durante los 6 meses anteriores a la evaluación (Kessler at al., 2005b). Los 4 primeros ítems investigan síntomas de inatención y los dos últimos de hiperactividad y se consideran puntuaciones criterio las tres primeras desde "a veces" a "muy frecuentemente", y las tres últimas desde "con frecuencia" a "muy frecuentemente". Cuatro respuestas en puntuaciones criterio se estiman sugestivas de existencia de TDAH en el adulto. La versión reducida en castellano está disponible en la web de la Universidad de Harvard (http:// www.hcp.med.harvard.edu/ncs/ftpdir/adhd/6Q-Spanish-USMexico.pdf), la versión completa en la web de la Universidad de Nueva York (http://www.med. nyu.edu/psych/assets/adhdscreen18.pdf) y también existen versiones completas en castellano disponibles en la red (http://www.deficitdeatencion.org/instrucciones.doc). 


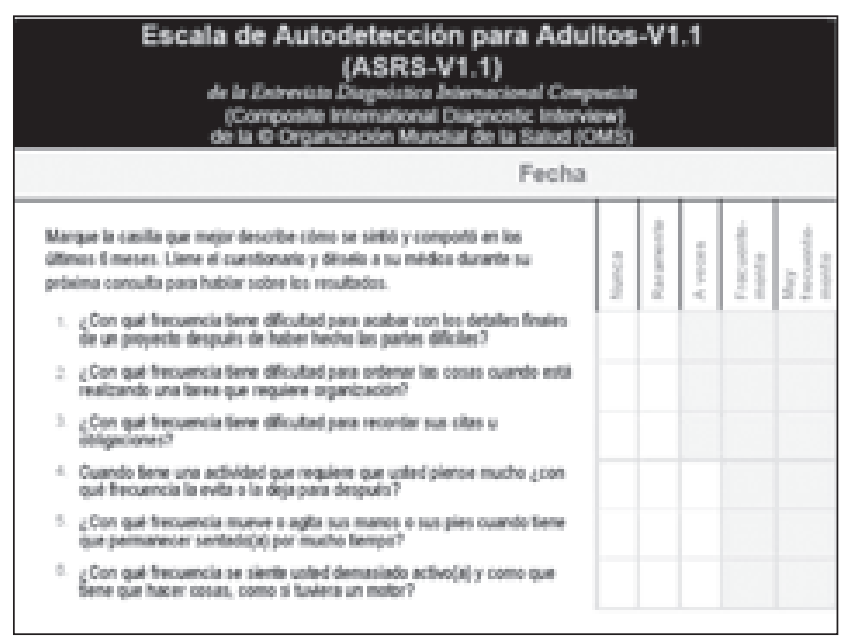

Figura 1. Versión española del ASRS v.1.1 Screening, de la OMS (Disponible en URL: http://www. hcp.med.harvard.edu/ncs/ftpdir/adhd/6Q-SpanishUSMexico.pdf.

Adult Attention Deficit-Hyperactivity Disorder Rating Scale IV (ADHD-RS-IV; DuPaul Power, Anastopoulos y Reid, 1998; Pappas, 2006), cuestionario que explora los 18 síntomas descritos en el DSM-IV para el trastorno, originalmente elaborado para la evaluación de niños, pero posteriormente aplicado en adultos. Se trata de una escala cuyos ítems coinciden plenamente con el listado de síntomas del criterio A del TDAH del DSM-IV. Por lo tanto, consta de una subescala de inatención (9 ítems), otra de hiperactividad/impulsividad (9 ítems) y la total (18 ítems). Cada ítem presenta cuatro opciones de respuesta: nunca, algunas veces, con frecuencia o con mucha frecuencia; las puntuaciones más elevadas son indicativas de presencia del síntoma. En el manual, la escala refiere excelentes indicadores de fiabilidad, validez, sensibilidad y especificidad, y se refrenda su uso tanto clínico como para estudios de prevalencia. La escala es utilizada para establecer el diagnóstico de TDAH, su severidad y la mejoría experimentada tras los tratamientos. No hemos encontrado estudios en adultos con la versión española, aunque sí en niños (Cardo y Servera, 2005; Cardo, Servera y Llobera, 2007).

Wender-Utah Rating Scale (WURS; Ward, Wender y Reimherr, 1993), cuestionario de 61 ítems puntuados según una escala de 5 opciones, del que los autores extrajeron 25 ítems que presentaban por sí mismos suficiente fiabilidad y capacidad discriminativa. Utilizamos estos 25 ítems en versión española (Ponce, Rodríguez, Pérez, Monasor, Rubio, Jiménez et al. 2000), que ha sido validada provisionalmente en población española (Rodríguez, Ponce Monasor, Jiménez, Pérez, Rubio, et al., 2001) y utilizada en población adicta (Pedrero, Puerta, Lagares y Pérez-López, 2004). Las preguntas se refieren todas a un encabezado común: "de pequeño yo era (o tenía, o estaba)», y se contestan desde 0 (nada) hasta 4 (mucho).
Millon Clinical Multiaxial Inventory-II (MCMI-II; Millon, 1999), cuestionario que consta de 175 ítems de respuesta verdadero-falso que informan sobre 8 patrones clínicos de personalidad, 3 formas graves de patología de personalidad, 6 síndromes clínicos de severidad moderada y 3 síndromes clínicos graves. Las puntuaciones directas, por una parte, permiten la descripción dimensional de los diversos patrones desadaptativos $y$, por otra, se convierten en puntuaciones de tasa base, atendiendo a la distribución de la prevalencia de cada trastorno en los subgrupos de población; la lógica de esta transformación se sitúa en el hecho que, a diferencia de los rasgos, que se distribuyen normalmente y con frecuencias comparables, los trastornos de personalidad no presentan una distribución semejante ni su prevalencia es igual entre las poblaciones de pacientes, lo que obliga a transformar las puntuaciones atendiendo al modelo de prevalencia subyacente a cada trastorno. Una vez considerado éste, mediante estudios poblacionales preliminares, el autor elabora unas tablas para cada subgrupo de población, estima un punto de corte en el valor 75 , siendo los valores iguales o superiores sugestivos de algún problema clínico, y otro en el valor 85 que indicaría una severidad importante del trastorno. El cuestionario cuenta con diversas medidas de validez, deseabilidad y sinceridad.

Proceso de Acogida y Valoración (PAV), instrumento de recogida de datos estandarizada para todos los Centros de Atención a Drogodependencias del Instituto de Adicciones de la Ciudad de Madrid (Ayuntamiento de Madrid). Se obtienen de él las variables sexo, edad, nivel de estudios alcanzado, droga que motiva la demanda, tiempo de consumo y criterios diagnósticos para el abuso/dependencia de sustancias.

Entrevistas diagnósticas explorando la presencia de criterios DSM-IV para TDAH y otras condiciones psicopatológicas. Estas entrevistas están precedidas de la administración de pruebas de autoinforme preliminares (cuestionarios SCID-I y SCID-II, Cuestionario Salamanca, WURS, Parents Rating Scale, etc.) que orientan el desarrollo y se realizan desde todas las áreas de trabajo (médica, psicológica, ocupacional y social) investigando las condiciones necesarias para formular un diagnóstico sobre los cinco ejes. Cuando es posible se incluye en algunas entrevistas a algún familiar (preferentemente la madre). Finalmente, se obtiene un juicio diagnóstico consensuado desde todas las áreas y formulado por el médico y el psicólogo.

\section{Procedimiento}

Se administra la versión reducida del ASRS v1.1 dentro de una batería de cuestionarios a todos los sujetos que inician tratamiento por abuso o dependencia de heroína, cocaína, alcohol o cannabis en un 
Centro de Atención a Drogodependencias (CAD-4 San Blas) del Instituto de Adicciones de Madrid Salud. La evaluación psicométrica se efectúa una vez que los sujetos se encuentran libres de sintomatología atribuible a los efectos de la droga o su retirada (lo que suele suceder entre la segunda y la cuarta semana desde la primera entrevista), y una vez establecida la existencia de criterios para estimar el diagnóstico de abuso o dependencia. Incorporado a esa batería se encuentra, en todos los casos, el MCMI-II y, sólo en algunos casos, la versión completa del ASRS v.1.1. ( $\mathrm{N}=85)$, el ADHD-RS ( $\mathrm{N}=64)$ o el WURS ( $\mathrm{N}=55)$. Con posterioridad se realizan entrevistas diagnósticas.

A las tres semanas de cumplimentado el cuestionario se efectúa un retest con la versión de 6 ítems a un subgrupo aleatorio de 60 sujetos para estudiar la estabilidad temporal.

Todos los participantes firman el consentimiento para la utilización anónima de los resultados en estudios de investigación.

\section{Análisis de datos}

Se utiliza el paquete estadístico SPSS 12.0. Se realizan pruebas de fiabilidad ( $\alpha$ de Cronbach, correlación test-retest), de validez factorial (análisis factorial exploratorio), de validez convergente y discriminante (utilizando pruebas no paramétricas cuando la distribución de las puntuaciones no se ajusta a la normalidad, como es el caso de las puntuaciones TB del MCMI-II), análisis descriptivos (sobre las variables sociodemográficas y de consumo) y validez diagnóstica (sensibilidad, especificidad, valor predictivo positivo y valor predictivo negativo).

\section{RESULTADOS}

\section{Fiabilidad}

La escala de 6 ítems ofrece una consistencia interna de 0,68 (0,92 para la versión completa de 18 ítems), medida por el coeficiente $\alpha$ de Cronbach. Si sólo consideráramos los 4 primeros ítems el $\alpha$ se incrementaría hasta 0,75: los ítems 5 y 6 presentan una muy baja correlación con el test, una vez excluidos de él (0,36 y 0,16, respectivamente). La estabilidad temporal de la versión reducida es de $r=0,74$ en un retest a los 21 días.

Las puntuaciones criteriales de ambas formas (completa y reducida) presentan un fuerte correlación ( $r=$ $0,76)$, que es aún mayor si consideramos las respuestas como una escala Likert entre 0 y 4 puntos $(r=0,93)$.

\section{Validez factorial}

Las pruebas de adecuación muestral nos indican la posibilidad de hacer un estudio factorial del cuestionario (medida de adecuación de Kaiser-Meyer-Olkin 0,67; prueba de esfericidad de Barlett $p<0,001)$. Efectuado un análisis de componentes principales aparecen dos factores con autovalores superiores a 1, que explican el 61,6\% de la varianza total del test. Efectuada una rotación Promax (asumiendo la teórica oblicuidad de los componentes), el primero agrupa a los 4 primeros ítems (cargas factoriales 0,79, 0,83, 0,64 y 0,73 , respectivamente) y el segundo a los ítems 5 y $6(0,79$ y 0,84$)$. El coeficiente $\alpha$ de Cronbach de los componentes 1 y 2 es, respectivamente, de 0,75 y 0,52 . La correlación entre ambos componentes es de $0,32(p<0,001)$.

Tabla 1. Análisis de componentes principales del ASRS 18 ítems. Solución no forzada de 4 factores y forzada de 2 factores.

\begin{tabular}{|c|c|c|c|c|c|c|c|}
\hline & \multicolumn{4}{|c|}{ Componentes } & & \multicolumn{2}{|c|}{ Componentes } \\
\hline & 1 & 2 & 3 & 4 & & 1 & 2 \\
\hline ITEM 02 & 0,90 & & & & Ítem 8 & 0,86 & \\
\hline ITEM 01 & 0,88 & & & & Ítem 9 & 0,80 & \\
\hline Ítem 17 & 0,80 & & & & ITEM 3 & 0,79 & \\
\hline Ítem 12 & 0,79 & & & & Ítem 11 & 0,78 & \\
\hline Ítem 08 & 0,77 & & & & Ítem 7 & 0,77 & \\
\hline Ítem 07 & 0,75 & & & & Ítem 12 & 0,76 & \\
\hline Ítem 10 & 0,71 & & & & ITEM 2 & 0,72 & \\
\hline ITEM 03 & 0,63 & & & & Ítem 10 & 0,71 & \\
\hline Ítem 09 & 0,63 & & & & ITEM 1 & 0,69 & \\
\hline Ítem 11 & 0,52 & 0,41 & & & Ítem 17 & 0,69 & 0,43 \\
\hline ITEM 04 & & 0,78 & & & Ítem 13 & 0,63 & 0,43 \\
\hline Ítem 14 & & 0,73 & & & ITEM 4 & 0,63 & \\
\hline Ítem 13 & & 0,47 & & & Ítem 14 & 0,48 & 0,45 \\
\hline Ítem 15 & & & 0,94 & & Ítem 16 & & 0,73 \\
\hline Ítem 16 & & & 0,82 & & Ítem 18 & & 0,68 \\
\hline Ítem 18 & 0,46 & & 0,53 & & ITEM 6 & & 0,61 \\
\hline ITEM 06 & & & & 0,95 & Ítem 15 & & 0,59 \\
\hline ITEM 05 & & & & 0,54 & ITEM 5 & & 0,58 \\
\hline
\end{tabular}

* Se han omitido las cargas factoriales inferiores a 0,40. 
Tabla 2. Correlaciones de Pearson entre los ítems del ADHD Rating Scale y la versión reducida del ASRS v.1.1 (N=64).

\begin{tabular}{|c|c|c|c|c|c|c|}
\hline & asrs_1 & asrs_2 & asrs_3 & asrs_4 & asrs_5 & asrs_6 \\
\hline adhd1 & $0,47 * * *$ & $0,55^{* * *}$ & $0,46 * * *$ & $0,51 * * *$ & $0,35 * *$ & $0,29 *$ \\
\hline adhd2 & $0,38 * *$ & $0,44 * *$ & $0,35^{* *}$ & $0,43^{* * *}$ & $0,82^{* * *}$ & $0,37^{* *}$ \\
\hline adhd3 & $0,49 * * *$ & $0,45^{* * *}$ & $0,50 * * *$ & $0,47^{* * *}$ & $0,35^{* *}$ & $0,36 * *$ \\
\hline adhd4 & $0,45 * * *$ & $0,43 * * *$ & $0,49 * * *$ & $0,51 * * *$ & $0,55 * * *$ & $0,45^{* * *}$ \\
\hline adhd5 & 0,16 & 0,21 & $0,34^{* *}$ & $0,38 * *$ & $0,27^{*}$ & $0,26^{*}$ \\
\hline adhd6 & $0,50 * *$ & $0,47^{* * *}$ & $0,41 * *$ & $0,55^{* * *}$ & $0,42 * *$ & $0,40 * *$ \\
\hline adhd7 & $0,78 * * *$ & $0,56^{* * *}$ & $0,38 * *$ & $0,69 * * *$ & $0,31^{*}$ & 0,18 \\
\hline adhd8 & $0,42 * *$ & $0,48 * * *$ & $0,30^{*}$ & $0,47 * * *$ & $0,42 * *$ & $0,33^{*}$ \\
\hline adhd9 & $0,64 * * *$ & $0,65^{* * *}$ & $0,41 * *$ & $0,61 * * *$ & $0,27^{*}$ & 0,09 \\
\hline adhd10 & $0,45^{* * *}$ & $0,37^{* *}$ & 0,10 & $0,31 *$ & $0,47^{* * *}$ & $0,61 * * *$ \\
\hline adhd11 & $0,70 * * *$ & $0,52 * * *$ & $0,41 * *$ & $0,66^{* * *}$ & 0,21 & 0,21 \\
\hline adhd12 & $0,36^{* *}$ & 0,18 & 0,24 & $0,28 *$ & $0,26^{*}$ & $0,41^{* *}$ \\
\hline adhd13 & 0,18 & $0,27^{*}$ & $0,61 * * *$ & $0,37^{* *}$ & $0,35^{* *}$ & 0,18 \\
\hline adhd14 & $0,38 * *$ & $0,31^{*}$ & $0,46 * *$ & $0,52^{* * *}$ & $0,41 * *$ & $0,37^{* *}$ \\
\hline adhd15 & $0,49 * * *$ & $0,54^{* * *}$ & $0,52^{* * *}$ & $0,66^{* * *}$ & $0,48 * * *$ & 0,22 \\
\hline adhd16 & $0,38 * *$ & $0,25^{*}$ & $0,36 * *$ & $0,45^{* * *}$ & $0,48 * * *$ & $0,40 * *$ \\
\hline adhd17 & $0,38 * *$ & $0,43 * * *$ & $0,65 * * *$ & $0,56^{* * *}$ & $0,47 * * *$ & $0,30 * *$ \\
\hline adhd18 & $0,38 * *$ & $0,36^{* *}$ & $0,34^{* *}$ & $0,46^{* * *}$ & $0,40 * *$ & $0,38 * *$ \\
\hline
\end{tabular}

$p<0,05 ; * * 0<0,01 ; * * * 0,001$.

Si llevamos a cabo las prueba sobre la versión completa aparecen cuatro factores que explican el $67 \%$ de la varianza total del test. Una solución forzada de 2 factores explicaría el $56 \%$ de la varianza y, tras una rotación Promax, agruparía los ítems en torno, por un lado, a los 4 primeros y, por otro, a los dos últimos, como puede observarse en la Tabla 1. El primero de los factores recogería todos los ítems referidos a problemas para mantener la atención y la organización de la conducta, mientras el segundo agruparía los de hiperactividad e intromisión en circunstancias sociales, si bien algunos ítems cargan fuertemente en ambos componentes, que presentan una significativa correlación entre sí $(r=0,29 ; p<0,01)$.

\section{Validez convergente}

Se administra el ADHD Rating Scale-IV a una submuestra de 64 sujetos. La correlación entre éste y la versión reducida del ASRS es de $r=0,77(p<0,001)$. Si utilizamos la versión completa del ASRS la correlación asciende a r=0,85. La correlación entre los ítems de ambas pruebas se muestra en la Tabla 2 .

Otra submuestra de 55 sujetos cumplimenta, simultáneamente al ASRS, la Wender Utah Rating Scale, versión de 25 ítems. La correlación entre ambos tests es de $r=0,46(p<0,01)$ para la versión reducida y de $r=0,42(p<0,01)$ para la versión completa. Sin embargo, si atendemos a los puntos de corte propuestos por los autores de ambos tests (36 para el WURS y 4 o más para el ASRS) sólo 5 de los 55 suje- tos $(9,1 \%)$ presentan puntuaciones criterio en ambos tests.

\section{Validez discriminante}

Se exploran a continuación las relaciones aparecidas entre las puntuaciones del ASRS y las del MCMIII. En la Tabla 3 se muestran las correlaciones entre la versión reducida del ASRS v.1.1, tanto en puntuaciones criteriales como en puntuaciones totales, con las escalas de trastornos de personalidad del MCMIII. Puede apreciarse la fuerte correlación positiva aparecida entre el test, en ambas versiones, y la mayor parte de las escalas de personalidad, en especial con todas las del espectro impulsivo y, en negativo, con la obsesiva y la dependiente.

Se efectúa seguidamente el mismo estudio de correlaciones, pero en esta ocasión utilizando los 6 ítems de la versión reducida del ASRS v.1.1. Puede apreciarse en la Tabla 4 cómo los cuatro primeros ítems, y muy especialmente el 1 y el 2, presentan fuertes, consistentes y muy significativas correlaciones con gran número de escalas de trastornos de personalidad, una vez más en positivo con las del espectro impulsivo y en negativo con la del obsesivo/compulsivo. Los ítems 4 y 5 , en cambio, apenas muestran relación significativa con las escalas del Eje II. Y también se observa el mismo patrón correlacional cuando utilizamos las puntuaciones a partir de los dos componentes obtenidos previamente mediante análisis factorial (componente 1: ítems 1 a 4; componente 2: ítems 5 y 6). Algo muy similar sucede con las escalas de síndromes clínicos del Eje I. 
Tabla 3. Correlaciones $\mathbf{r}$ de Spearman entre las puntuaciones directas y las puntuaciones criteriales del ASRS v1.1 y las escalas de trastornos de la personalidad del MCMI-II $(\mathbf{N}=\mathbf{2 8 0})$.

\begin{tabular}{lcc}
\hline & Puntuación total ASRS 6 & Puntuación criterial ASRS 6 \\
\hline ESQUIZOIDE & 0,05 & $0,20^{* * *}$ \\
EVITATIVO & $0,21^{* * *}$ & $0,37^{* * *}$ \\
DEPENDIENTE & $-0,07$ & $-0,08$ \\
HISTRIÓNICO & $-0,01$ & 0,08 \\
NARCISISTA & 0,1 & $0,22^{* * *}$ \\
ANTISOCIAL & $0,26^{* * *}$ & $0,43^{* * *}$ \\
AGRESIVO & 0,11 & $0,27^{* * *}$ \\
OBSESIVO & $-0,30^{* * *}$ & $-0,31^{* * *}$ \\
NEGATIVISTA & $0,28^{* * *}$ & $0,44^{* * *}$ \\
AUTODESTRUCTIVO & $0,38^{* * *}$ \\
ESOUIZOTÍPICO & $0,29 * *$ & $0,32^{* * *}$ \\
LÍMITE & $0,19 * *$ & $0,40^{* * *}$ \\
PARANOIDE & $0,29^{* * *}$ & $0,20^{* * *}$ \\
\hline
\end{tabular}

$p<0,05 ;{ }^{*} p<0,01 ; * * * 0<0,001$.

Tabla 4. Correlaciones $r$ de Spearman entre los ítems del ASRS v1.1 y los dos componentes extraídos mediante análisis factorial, con las escalas del MCMI-II ( $\mathbf{N = 2 8 0 ) . ~}$

\begin{tabular}{|c|c|c|c|c|c|c|c|c|}
\hline & \multicolumn{6}{|c|}{ Ítems del ASRS v1.1 } & \multicolumn{2}{|c|}{ Componentes } \\
\hline & asrs_1 & asrs_2 & asrs_3 & asrs_4 & asrs_5 & asrs_6 & FACTOR 1 & FACTOR 2 \\
\hline ESQUIZOIDE & $0,13^{*}$ & 0,10 & $0,12^{*}$ & 0,10 & $-0,10$ & $-0,20 * *$ & $0,15^{*}$ & $-0,17^{* *}$ \\
\hline EVITATIVO & $0,27^{* * *}$ & $0,25 * * *$ & $0,18 * *$ & $0,23 * * *$ & $-0,03$ & $-0,08$ & $0,29 * * *$ & $-0,06$ \\
\hline DEPENDIENTE & $-0,09$ & $-0,11$ & $-0,09$ & $-0,02$ & $-0,10$ & $-0,04$ & $-0,09$ & $-0,10$ \\
\hline HISTRIÓNICO & 0,06 & $-0,02$ & $-0,11$ & 0,03 & $-0,02$ & $-0,01$ & $-0,03$ & $-0,04$ \\
\hline NARCISISTA & $0,12^{*}$ & 0,04 & 0,03 & 0,03 & 0,06 & 0,07 & 0,06 & 0,06 \\
\hline ANTISOCIAL & $0,28 * * *$ & $0,22 * * *$ & $0,13^{*}$ & $0,21 * * *$ & 0,11 & 0,00 & $0,27 * * *$ & 0,06 \\
\hline AGRESIVO & $0,15^{*}$ & 0,11 & 0,06 & 0,09 & 0,05 & 0,02 & 0,11 & 0,04 \\
\hline OBSESIVO & $-0,28 * * *$ & $-0,27 * *$ & $-0,15^{*}$ & $-0,25 * * *$ & $-0,20 * *$ & 0,01 & $-0,32 * * *$ & $-0,11$ \\
\hline NEGATIVISTA & $0,29 * * *$ & $0,27 * *$ & $0,21 * * *$ & $0,25 * * *$ & 0,09 & 0,01 & $0,32 * * *$ & 0,06 \\
\hline AUTODESTRUCTIVO & $0,30 * *$ & $0,29 * * *$ & $0,20^{* *}$ & $0,30 * * *$ & 0,09 & $-0,02$ & $0,35 * * *$ & 0,04 \\
\hline ESQUIZOTÍPICO & $0,24 * * *$ & $0,17^{* *}$ & $0,17^{* *}$ & $0,22 * * *$ & 0,02 & $-0,06$ & $0,26 * * *$ & $-0,02$ \\
\hline LÍMITE & $0,31 * * *$ & $0,27 * *$ & $0,14^{*}$ & $0,25 * * *$ & 0,07 & $-0,01$ & $0,31 * * *$ & 0,03 \\
\hline PARANOIDE & 0,06 & 0,00 & 0,07 & 0,02 & 0,01 & 0,06 & 0,05 & 0,03 \\
\hline ANSIEDAD & $0,21^{* * *}$ & $0,20 * *$ & $0,22 * * *$ & $0,17^{* *}$ & 0,1 & $-0,02$ & $0,24^{* * *}$ & 0,06 \\
\hline SOMATOFORME & 0,12 & $0,13^{*}$ & 0,1 & 0,11 & 0,06 & $-0,03$ & $0,15^{*}$ & 0,02 \\
\hline HIPOMANIA & 0,11 & 0,08 & 0,02 & 0,08 & 0,02 & 0,04 & 0,08 & 0,02 \\
\hline DISTIMIA & $0,17 * *$ & $0,14^{*}$ & $0,15^{*}$ & $0,15^{*}$ & 0,01 & $-0,07$ & $0,18 * *$ & $-0,03$ \\
\hline ABUSO ALCOHOL & $0,21 * * *$ & $0,19 * *$ & $0,13^{*}$ & $0,22 * * *$ & 0,05 & $-0,1$ & $0,23 * * *$ & $-0,02$ \\
\hline ABUSO DROGAS & $0,29 * * *$ & $0,24 * *$ & $0,14^{*}$ & $0,23^{* * *}$ & 0,11 & 0,01 & $0,28 * * *$ & 0,06 \\
\hline PENSAMIENTO PSICÓTICO & $0,20 * *$ & $0,19 * *$ & $0,21 * * *$ & $0,18^{* *}$ & 0,07 & 0,04 & $0,25^{* * *}$ & 0,07 \\
\hline DEPRESIÓN MAYOR & $0,29 * *$ & $0,28 * *$ & $0,17^{* *}$ & $0,26 * * *$ & 0,07 & $-0,07$ & $0,32 * * *$ & 0,00 \\
\hline TRASTORNO DELIRANTE & 0,02 & $-0,05$ & 0,05 & 0 & 0,01 & 0,07 & 0,01 & 0,05 \\
\hline
\end{tabular}

$p<0,05 ; *{ }^{*} p<0,01 ; * * * 0,001$. 


\section{Validez criterial}

En la Figura 2 se observa la distribución de las puntuaciones obtenidas por la muestra de sujetos adictos en tratamiento en el ASRS (versión de 6 ítems): un 19,3\% alcanza o supera la puntuación de corte de 4 respuestas criterio. El porcentaje de consumidores de cocaína que puntúan 4 o más es mayor, aunque no hay significación estadística en las diferencias según droga (pruebas de $\chi^{2}, p=0,65$ ), salvo que efectuemos las comparaciones entre los grupos excluyendo al de consumidores de cannabis $(\mathrm{N}=14)$, apareciendo entonces significación $(p<0,05)$. En la figura 3 se considera la variable sexo, y se observa que las consumidoras de cocaína ( $\mathrm{N}=24)$ alcanzan puntuación criterio en un porcentaje mayor $(25,0 \%)$ que los varones $(16,8 \%)$, aunque las diferencias no son significativas (test de Fisher, $p=0,22$ ). Lo mismo sucede con las mujeres que son tratadas por consumo de alcohol, que puntúan más $(36,4 \%)$ que los varones en la misma situación $(23,3 \%)$, si bien tampoco en este caso aparece significación $(p=0,28)$. La mitad de las mujeres en tratamiento por cannabis obtienen puntuaciones criterio de TDAH, por ninguno de los 10 varones, aunque los datos son irrelevantes dado lo exiguo de la muestra (4 mujeres y 10 varones).

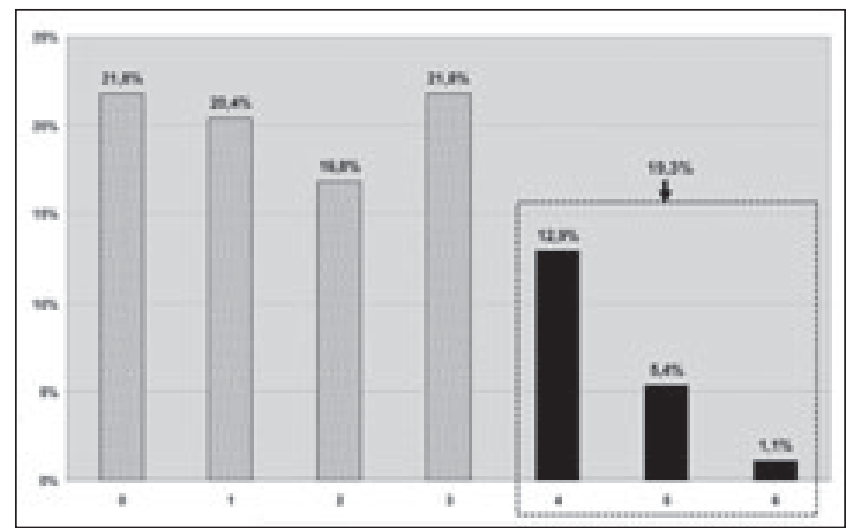

Figura 2. Porcentaje de sujetos de la muestra total que obtienen puntuaciones criterio $(\geq 4)$ en el ASRS, versión de 6 ítems $(\mathrm{N}=280)$.

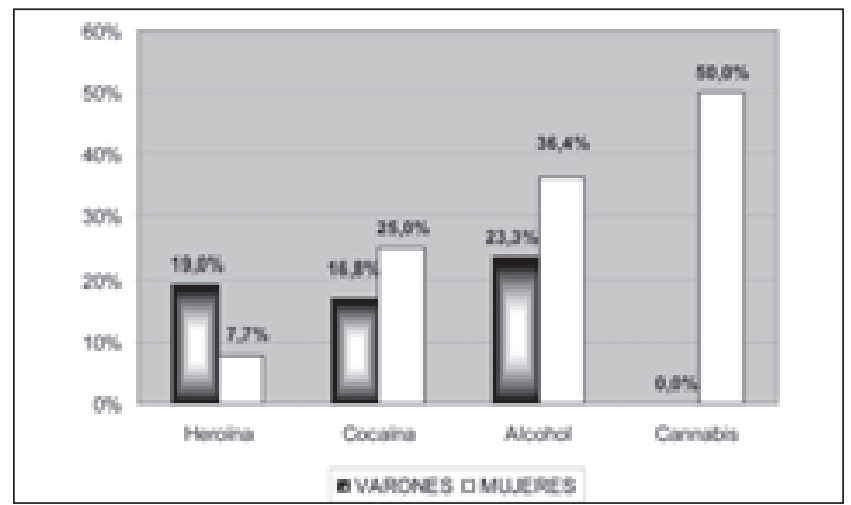

Figura 3. Porcentaje de sujetos que alcanzan puntuaciones criterio $(>3)$ en el ASRS para estimar presencia de TDAH, según sexo y droga principal (Varones $\mathbf{N}=218$; Mujeres $\mathrm{N}=62$ ).
La puntuación del ASRS v.1.1 reducida no presenta correlación significativa con la edad $(r=-0,11)$ ni con el tiempo de consumo de la droga principal $(r=0,07)$, aunque sí con el nivel de estudios $(r=-0,14 ; p<0,05)$.

Se procede a continuación a conocer los diagnósticos emitidos tras las entrevistas clínicas. El 8,2\% de la muestra total presenta criterios DSM-IV para el diagnóstico de TDAH: se trata de 18 varones $(8,3 \%)$ y 5 mujeres (8,1\%). Suponen el 7,1\% de los consumidores varones de heroína (ninguna mujer en tratamiento por esta droga recibe el diagnóstico de TDAH); el $10,8 \%$ de los varones y el $12,5 \%$ de las mujeres consumidores de cocaína; el 6,3\% de los varones y el $4,8 \%$ de las mujeres en tratamiento por consumo de alcohol; y el $10 \%$ de los varones y el $25 \%$ de las consumidoras de cannabis.

De entre quienes obtuvieron puntuaciones criterio en el ASRS y no recibieron el diagnóstico de TDAH, el 100\% recibió algún diagnóstico alternativo (en algunos casos, se superpusieron diagnósticos en los Ejes I y II): Trastorno de Ansiedad Generalizada (33,3\%), Trastorno de Personalidad Negativista/Pasivo-Agresiva $(22,2 \%)$, Trastorno de Personalidad por Evitación (19,4\%), Trastorno Límite de Personalidad (19,4\%), Trastorno Bipolar (5,6\%), Trastorno Antisocial de la Personalidad (5,6\%), Esquizofrenia (2,8\%), Trastorno de Personalidad Narcisista (2,8\%), Trastorno Histriónico de la Personalidad (2,8\%) y Trastorno de Personalidad Paranoide (2,8\%).

Para quienes sí recibieron el diagnóstico de TDAH, se encontraron los siguientes diagnósticos concurrentes: Trastorno Antisocial de la Personalidad (34,8\%), Trastorno de Personalidad Negativista/Pasivo-Agresiva (22,2\%), Trastorno de Ansiedad Generalizada (17,4\%), Trastorno de Personalidad Narcisista (8,7\%), Trastorno Límite de Personalidad (4,3\%) y Trastorno Histriónico de la Personalidad (4,3\%). El 21,7\% no recibió ningún diagnóstico adicional (a excepción, por supuesto, del de abuso/dependencia de sustancias).

De las 23 personas que fueron diagnosticadas de TDAH, 18 habían alcanzado o superado el punto de corte en el ASRS, de 4 o más ítems en puntuaciones criterio, mientras 4 más habían obtenido 3 puntos y una 2 puntos. Esto supone una sensibilidad del $78,3 \%$, que ascendería al $95,7 \%$ si tomáramos como referencia el punto de corte de 3 ítems. La especificidad es del $86 \%$, aunque descendería drásticamente al $63,8 \%$ si utilizáramos el punto de corte de 3 ítems. El valor predictivo positivo es del 42,6\% (19,1\% para el punto de corte 3) y el valor predictivo negativo es del $97,8 \%(99,4 \%$ para el punto de corte 3$)$. 


\section{DISCUSIÓN}

EI ASRS v.1.1. mostró, en su versión completa, una adecuada fiabilidad. La versión reducida de 6 ítems no presentó, por razones obvias, tal fiabilidad, pero, según informan estudios ya citados, ofrece una mayor sensibilidad y especificidad, lo que permite su utilización con suficientes garantías. Nuestros datos aportan incluso porcentajes superiores para la sensibilidad, que sería, según esos estudios (Kessler et al., 2005) del 68,7\%, y alcanzan el 78,3\% en nuestro estudio. La especificidad, en cambio, fue menor en nuestro estudio, del 86\%, frente al 99,5\% encontrado en el citado trabajo. Es significativo que, según nuestros datos, si se utiliza el punto de corte de 3 ítems la sensibilidad asciende al 95,7\%, aunque a costa de disminuir drásticamente la especificidad $(63,8 \%)$. Este dato es importante en la medida en que cada punto de corte es más útil en función del objetivo que persiga su utilización: para estudios que busquen estimar la prevalencia sería más adecuado adoptar el punto de corte de 4 ítems, pero si lo que queremos es aislar a aquellos sujetos que pueden presentar un TDAH, de cara a profundizar en la evaluación y formular objetivos individualizados de tratamiento, habría que considerar el punto de corte de 3. Esto nos proporcionaría más falsos positivos, pero, como nuestros datos también sugieren, nos permitiría aislar a sujetos con otro tipo de psicopatología cuya evaluación también sería relevante.

Un estudio más detallado del cuestionario nos proporciona información adicional. Tanto en la versión completa como en la reducida, parecen existir dos componentes diferenciados: uno, el que se configura a partir de los primeros cuatro ítems, y otro que se agrupa en torno a los ítems 5 y 6 . Ambos presentan, por separado, una adecuada fiabilidad $(0,75$ y 0,52 , respectivamente) pero al combinarse en el cuestionario de 6 ítems proporcionan un test con dos medidas con una pobre correlación $(r=0,29)$. Los primeros cuatro ítems miden síntomas relacionados con la dificultad para finalizar tareas complejas, para organizar la conducta hacia metas complicadas, para mantener la memoria de trabajo o la tendencia a la procrastinación ante tales dificultades. Los dos últimos, en cambio, interrogan sobre síntomas específicos de hiperactividad motora. Cabe esperar que ambas medidas debieran mostrar una correlación más estrecha si lo que pretenden medir es un síndrome que se define por la presencia de ambas.

La convergencia entre el ASRS de 6 ítems y el ADHD-RS-IV fue elevada $(r=0,77)$, lo que nos informa de lo adecuado del primero para estimar la misma variable que el segundo, tanto más cuanto que el ADHD-RS-IV se trata de una escala cuyos ítems coinciden plenamente con el listado de síntomas del criterio A del TDAH del DSM-IV: cada uno de sus 18 ítems interroga directamente con cada uno de los 18 elementos criteriales de la clasificación. No fue tan potente ni significativa la correlación con el WURS, como era de esperar, puesto que éste no interroga sobre sintomatología actual, sino la existente en el pasado. Además, muchos de los ítems de la versión reducida del WURS exploran problemas afectivos y emocionales que no forman parte de los criterios DSM-IV para el TDAH (Pedrero et al., 2004).

El estudio de las correlaciones entre el ASRS y el MCMI-II proporcionó también información relevante. Cabría esperar que los resultados fueran una prueba de validez discriminante, en la medida en que uno pretende medir un trastorno del Eje I, caracterizado por inatención, hiperactividad e impulsividad, y el otro diversos trastornos del Eje II, definidos por patrones complejos de conducta. Sin embargo, encontramos fuertes correlaciones entre las medidas, tomadas en puntuaciones escalares o criteriales, con casi todos los trastornos de personalidad. Dicho de otro modo: lo que el ASRS v1.1. está midiendo es un grupo de condiciones que son comunes a una buena parte de los trastornos de la personalidad. Esto queda matizado al estudiar las correlaciones ítem a ítem: son los cuatro primeros ítems del ASRS los que son comunes a la mayor parte de las escalas de personalidad desadaptativa. Los dos últimos, en cambio, miden algo sensiblemente diferente.

La relación con los trastornos no es positiva en todos los casos: los trastornos dependiente y obsesivo/compulsivo presentaron correlaciones negativas. En realidad, lo que estos ítems están midiendo, según parece, es una dimensión general de impulsividad que supone el sustrato dimensional de los trastornos de personalidad. Los resultados están de acuerdo con recientes estudios que encuentran distribuciones dimensionales de los trastornos de personalidad (Pedrero, López-Durán y Olivar, 2006) que configuran clusters diferentes a los admitidos y propuestos por el DSM (Inda, Lemos, Paíno, Besteiro, Alonso, Bobes et al., 2006) y coherentes con propuestas que encuentran un espectro continuo entre los trastornos compulsivos y los trastornos impulsivos (Hollander y Wong, 1995; McElroy, Hudson, Phillips, Keck y Pope, 1993). Así, los cuatro primeros ítems del ASRS correlacionarían negativamente con el polo compulsivo, no mantendrían correlación con los trastornos intermedios menos severos (dependiente, histriónico y narcisista) e irían covariando positivamente con mayor fuerza a medida que se aproximaran a los trastornos más severos, tanto del espectro impulsivo "de ataque" (antisocial, negativista y límite) como del espectro esquizofreniforme con el impulso "de huida" (esquizoide, esquizotípico, autodestructivo y evitativo).

Los ítems 5 y 6, por el contrario, sí están midiendo algo que no está implícito en las escalas de trastornos de personalidad. Muestran muy bajas correlaciones, 
aunque también en el sentido del eje compulsividad/ impulsividad ya mencionado. Estos dos ítems interrogan sobre síntomas de hiperactividad en sentido estricto: incapacidad para permanecer quieto y sobreactivación motora.

Nos encontramos, pues, ante un cuestionario que a pesar de ajustarse escrupulosamente a los criterios DSM-IV (o precisamente por ello) imposibilita la detección específica de un trastorno al utilizar criterios inespecíficos que pueden ser indicativos de muchos trastornos (del Eje I o del Eje II) o consecuencia de ellos. Algo similar sucedía cuando, en un estudio previo (Pedrero et al., 2004) estudiábamos el WURS, pero en esta ocasión con el añadido de que más de la mitad de los ítems exploraban síntomas de tipo emocional que ni siquiera se encontraban recogidos en los criterios DSM-IV para el trastorno que pretendían evaluar.

El principal problema de los criterios DSM, según están formulados en la actualidad, es la trasgresión epistemológica y semiológica que generan en su interpretación. La impulsividad, que se requiere como síntoma (manifestación subjetiva de malestar) se interpreta como signo (manifestación constatada por el observador) y se confunde con rasgo (elemento característico de la personalidad relativamente estable). Los criterios DSM exigen que la impulsividad se presente en forma de síntomas, esto es, que la persona les atribuya una relación con su malestar, mientras que todos los cuestionarios utilizados en la detección, actual y pasada, del TDAH en el adulto exploran determinadas conductas como signos que avalan la existencia del trastorno, independientemente de que estén o no relacionados con malestar subjetivo. Además, para asegurar la existencia de estos "síntomas" muchos estudios recurren a la utilización de cuestionarios que exploran la impulsividad como rasgo o estilo personal (p.e., escalas de Barrat, de Dickman, de Plutchik). La impulsividad ha sido estudiada ampliamente como componente funcional o disfuncional de la personalidad, de modo que la detección de rasgos impulsivos no está necesariamente ligada a procesos patológicos, sino que puede ser, en combinación con otros rasgos, perfectamente adaptativa aun cuando se presente en magnitudes elevadas. En los estudios sobre TDAH en el adulto, por el contrario, la detección de un rasgo de impulsividad se toma por prueba suplementaria de existencia del trastorno.

Lo mismo puede decirse de los problemas de atención. Lo que el DSM exige que sea un "síntoma" queda restringido a la mera observación o declaración de conductas que denotan inatención, independientemente de que éstas generen o no malestar significativo. Es preciso recordar que "la mera observación de conductas de falta de atención (distracción, movimiento de pies y manos, cansancio, errores, etc.) no es indicativa de la presencia de un déficit en el funcionamiento de los mecanismos de amplitud o intensidad atencional" y que, tras descartar factores organísmicos (p.e., déficits sensoriales), características personales (como el temperamento, determinados rasgos de personalidad o, muy especialmente, la capacidad de autocontrol: la impulsividad motora, los problemas para demorar gratificaciones o la poca tolerancia a la frustración) o algunos estados transitorios (p.e., la fatiga o el estrés), "es necesario aplicar pruebas atencionales específicas de amplitud (selección/focalización y cambio atencional) y/o intensidad (capacidad de mantenimiento) con índices psicométricos suficientes" para valorar un déficit atencional (Servera y Galván, 2001; pp. 66-67).

Lo que los 4 primeros ítems del ASRS v.1.1. miden, pues, es la declaración de conductas que denotan fallos atencionales, o errores en la programación de la actividad, o falta de persistencia en tareas con dificultad, que pueden ser explicadas por múltiples factores, no necesariamente por la existencia de un TDAH. Por ejemplo, por estados o síndromes depresivos, lo que explicaría tales déficits a partir de la anhedonia, la apatía o la falta de energía inherente a estos cuadros; es preciso hacer notar las significativas correlaciones entre estos 4 ítems con las escalas de distimia y depresión mayor (entre otras) del MCMI-II. Sin olvidar que otros trastornos, como el de estrés postraumático, provocan déficits atencionales similares a los del TDAH, a partir de inputs emocionales sobre la misma zona de la corteza frontal implicada en éste (Vasterling, Duke, Brailey, Constans, Allain y Sutker, 2002). Los ítems 5 y 6, en cambio, sí parecen explorar conductas específicamente hiperactivas e independientes de factores emocionales o de rasgos de personalidad.

A partir de nuestros datos, y considerando que los criterios DSM son los que son, y que el ASRS v.1.1. se ajusta a ellos, encontramos en nuestra muestra que un $19,3 \%$ presenta, en los seis meses anteriores a la evaluación, suficientes conductas para que, a partir del criterio A del DSM-IV-TR, pueda sospecharse la existencia de un TDAH. En un estudio precedente con el mismo instrumento (Pedrero y Puerta, 2006) encontrábamos una prevalencia similar, aunque algo menor, del $16 \%$, si bien en esta ocasión la muestra estaba compuesta por sujetos que se encontraban ya en tratamiento y no, como en el trabajo presente, en las fases iniciales de éste. Aunque se trata de muestras diferentes puede formularse la hipótesis de que la frecuencia de conductas exploradas por el ASRS disminuye a medida que la evaluación se aleja en el tiempo de la fase de consumo activo; y, por consiguiente, también puede hipotetizarse que el consumo activo provoca conductas que se asemejan o simulan las que definen al TDAH según los criterios vigentes.

Pero el DSM no prescribe únicamente el criterio A: obliga también, según el criterio $B$, a constatar que tales síntomas estaban ya presentes en edades tempranas, antes de los 7 años. Cuando en las entre- 
vistas se explora este criterio la prevalencia cae drásticamente: muchos de los sujetos y, sobre todo sus familiares cercanos (madre, principalmente), informan de la inexistencia de este tipo de problemas antes de los 10 años. Diversos autores abogan por la abolición de este criterio, que consideran muy restrictivo, en la medida en que los sujetos con inicio tardío presentan similares síntomas de TDAH, similares patrones de deterioro neurocognitivo y similar comorbilidad psicopatológica (Faraone, Biederman, Doyle, Murray, Petty, Adamson et al., 2006; Faraone, Biederman, Spencer, Mick, Murria, Petty et al., 2006; Rohde, Biederman, Zimmermann, Schmilz, Martins y Tramontina, 2000). En nuestra opinión, desproveer a la categoría diagnóstica de este criterio equivaldría a construir un saco sin fondo en el que prácticamente podría incluirse a cualquier sujeto impulsivo, inquieto, ansioso (de ansia, más que de ansiedad), indócil o despistado. La única consecuencia inmediata sería la generalización de los tratamientos farmacológicos, lo cual no es un objetivo descartable para unos autores (en especial Faraone y Biederman) que declaran tan amplios conflictos de intereses por su fuerte vinculación con la industria farmacéutica (ver Faraone et al., 2006). En definitiva, lo que hace al TDAH ser una categoría clínicamente útil no es sólo conocer su presentación fenomenológica, sino los sustratos neurobiológicos que lo justifican, la presentación temprana de sus manifestaciones y el curso temporal que puede explicar los signos y conductas presentes en la edad adulta. No es descartable que tales signos y manifestaciones puedan tener causas diferentes (ya hemos mencionado el trastorno por estrés postraumático como una de ellas) pero no parece que juntar todas las posibles presentaciones en una categoría fenomenológica ayude a la investigación ni a la clínica.

Además, el criterio E del DSM excluye explícitamente el diagnóstico de TDAH cuando los "síntomas" pueden ser mejor explicados por otro trastorno, incluyendo entre los ejemplos los del estado de ánimo, de ansiedad y de personalidad. Cualquier estudio que omita la evaluación concomitante de la psicopatología del Eje I y del Eje II estará transgrediendo gravemente los criterios diagnósticos explicitados en el DSM-IV-TR. En nuestro estudio hemos utilizado el MCMI-II, que evalúa la probabilidad de existencia de tales trastornos en ambos ejes, aunque no proporciona de forma automática un diagnóstico. Las entrevistas diagnósticas posteriores sí nos han permitido discernir si, por ejemplo, el trastorno de ansiedad generalizada (TAG), uno de los más frecuentemente detectados, explicaba por sí mismo el deterioro atencional y la inquietud motora, o bien era una condición coexistente con un TDAH instaurado con anterioridad. Hay que hacer notar que entre los criterios del TAG se encuentran: inquietud o impaciencia, fatigabilidad, dificultad para concentrarse o tener le mente en blan- co, irritabilidad, tensión muscular, alteraciones del sueño, que provocan malestar significativo o deterioro social, laboral o de otras áreas importantes de la actividad del individuo. La superposición con los signos y síntomas del TDAH es evidente. Si omitiéramos el criterio de inicio temprano en la infancia ¿deberíamos tratar a estos sujetos con las mismas terapias que a IOS TDAH?

Quedarían aún dos criterios más que el DSM exige para dar por aceptable el diagnóstico de TDAH en los sujetos de nuestra muestra, y cuya aplicación posiblemente disminuiría aún más la ya exigua prevalencia observada. El criterio C exige que los "síntomas" se presenten en al menos dos ambientes y el criterio D exige que causen deterioro clínicamente significativo de la actividad social, académica o laboral. En nuestra muestra, al tratarse de sujetos que acuden solicitando tratamiento por abuso o dependencia de sustancias, es previsible que ambos criterios se cumplan en la práctica totalidad de los casos. Pero, al mismo tiempo, es difícil sostener que tales dificultades deban atribuirse al TDAH y no más propiamente a la adicción.

Nuestras cifras de prevalencia encontradas se sitúan por debajo de las propuestas para población adicta, que suelen estimarse entre el 15 y el $25 \%$ (Wilens, 2004), si bien están más próximas, e incluso superan, a las encontradas en otros estudios que aplican métodos rigurosos de diagnóstico, aunque soportan elevados porcentajes de mortalidad experimental, y que apenas superan el 7\% (Goossensen et al., 2006). Las razones para estas diferencias, que suponen un severo contratiempo para efectuar un estudio comparativo de prevalencia, son dos, fundamentalmente: (1) el rigor metodológico de los procesos diagnósticos; y (2) el tipo de población que participa en el estudio. En cuanto al primero, ya ha sido discutido, y es obvio que cuanto más laxa sea la aplicación de los criterios diagnósticos más abultadas serán las cifras de prevalencia. En relación al segundo criterio, es importante tener en cuenta sobre qué población se desarrolla el estudio, es evidente que las cifras de prevalencia no pueden ser similares si se estudian muestras hospitalarias, que han acudido por presentar complicaciones en el proceso de tratamiento de su adicción, o en muestras de sujetos ingresados en dispositivos residenciales como las comunidades terapéuticas, a los que han sido derivados precisamente por la complejidad de su problemática, que si estudiamos, como es el caso del presente estudio, muestras de sujetos que acuden a un dispositivo específico de primer nivel, consumiendo diversas sustancias, con diferentes grados de severidad, donde se aborda una evaluación primaria de su proceso adictivo y de las condiciones coexistentes con la adicción. Nuestros datos sugieren que el $8,2 \%$ de todos estos sujetos, que inician un tratamiento por problemas asociados al consumo de sustancias, cumplen criterios de TDAH, 
y que este porcentaje se concentra más en los consumidores de cocaína, entre el 11 y el 13\% según el sexo.

Para llegar a esta cifra se han tenido que cumplir los criterios DSM en relación a la existencia de otras condiciones que explicaran mejor los elementos observados del trastorno. Y para ello ha sido preciso entrar en el áspero territorio de la comorbilidad, y no hay que olvidar que "por lo menos en parte, la comorbilidad no deja de ser un artefacto conceptual derivado de la forma arbitraria en que se han definido los trastornos mentales en el DSM IV. Puesto que en muchos trastornos el substrato biológico está lejos de ser unitario y delimitado, las definiciones y criterios diagnósticos parten de realidades observables, que con mayor o menor acierto han intentado clasificarse y sistematizarse. Pero no olvidemos que las definiciones van variando a lo largo del tiempo, que no son universalmente aceptadas y sobre todo, que la naturaleza no tiene ningún motivo ni ningún interés en ajustarse a ellas" (Artigas, García y Rigau, 2003). Por ello, es arriesgado considerar que la mera existencia de criterios para diagnosticar la existencia de dos o más trastornos suponga una prueba de comorbilidad. Una de las categorías más frecuentemente asociadas al TDAH es la de los trastornos de la personalidad, y es fácilmente entendible que personas que tienen severas dificultades para relacionarse con otros, para circular adecuadamente por el sistema educativo y que, en virtud de determinadas configuraciones de su sistema nervioso central, han recibido más dosis de castigo y menor de reforzamiento que sus iguales, desarrollen patrones de personalidad con más o menos disfunciones. Sin embargo, el TDAH no es la única condición que explicaría la génesis de estos patrones disfuncionales de personalidad. Es preciso conocer si la disfunción se origina desde edades tempranas y desemboca en un trastorno de la personalidad, o bien si no existen pruebas sólidas de que hubiera disfunciones que precedieran a las fases críticas de formación de la personalidad por más que la construcción disfuncional de ésta derivara en una configuración sindrómica similar a la del TDAH. Sería entonces más adecuado suponer la existencia de un Trastorno por Disfunción Prefrontal, con subtipos de base estructural (TDAH) y otros de base funcional.

De nuestros resultados cabe destacar tres condiciones diagnósticas. En primer lugar, el Trastorno de Personalidad Negativista-Pasivo/Agresivo, que se presenta por encima del $20 \%$ tanto como diagnóstico coexistente con el TDAH como en calidad de categoría que explicaría mejor el cuadro sindrómico observado. Se trata de una categoría actualmente propuesta para estudio y, en virtud de ello, muy poco estudiada en la medida en que los estudios suelen limitarse únicamente a los trastornos actualmente admitidos en el DSM-IV; que además, cuando se estudia, aparece sis- temáticamente presente como uno de los más prevalentes en población adicta, y que aparece en muchos casos como una forma menor de Trastorno Límite y, en otras, como una modalidad de Trastorno Antisocial, aunque con suficientes elementos propios como para ser claramente diferenciados; y que se corresponde casi por superposición de criterios al Trastorno Negativista Desafiante, frecuentemente diagnosticado a niños y adolescentes y frecuentemente asociado al TDAH, aunque no necesariamente derivado de éste (Pedrero et al., 2006).

En segundo lugar, casi el $20 \%$ de los sujetos que tienen manifestaciones similares a las del TDAH, pero sin presentación temprana, son diagnosticados alternativamente de Trastorno de Personalidad por Evitación. Las características que se atribuyen a esta categoría incluyen un permanente estado de alerta que les lleva a estar escaneando permanentemente el entorno en la búsqueda ansiosa de peligros, reales, potenciales o imaginarios, lo que compromete seriamente sus procesos de atención y generan un estado persistente de agitación e intranquilidad, y una tendencia al impulso de huida (escape o evitación) ante cualquier señal de peligro (Millon y Davis, 1998). Y, en tercer lugar, el Trastorno de Ansiedad Generalizada, con características muy similares al Trastorno de Personalidad por Evitación, pero supuestamente más limitado en el tiempo, aunque difícilmente distinguibles cuando el primero se prolonga en el tiempo. En un tercio de los casos este trastorno explica mejor que el TDAH el cuadro sindrómico observado, pero en más del $17 \%$ es una condición añadida. Los trastornos de ansiedad, en el que se incluye el Trastorno de Estrés Postraumático, mencionado líneas más arriba, pueden dar cuenta de los problemas de atención, impulsividad y activación motora que pueden confundirse con un TDAH en el adulto.

En conclusión, el ASRS v.1.1. es un cuestionario sencillo y útil para detectar la presencia reciente de indicadores de TDAH, según éstos son formulados por el DSM-IV-TR. Puede ser utilizado como screening preliminar para detectar a sujetos que cumplan tales criterios, presentando adecuados valores de sensibilidad y especificidad. Sin embargo, su utilidad para orientar un diagnóstico de TDAH en el adulto es muy limitada, no tanto por características inherentes al propio cuestionario, sino principalmente por la inespecificidad de los criterios DSM para formularlo. Sólo los ítems 5 y 6 de la versión reducida del ASRS parecen explorar conductas específicamente hiperactivas, en tanto que el resto de ítems (los cuatro primeros de la versión reducida y al menos 9 de los 12 restantes de la versión completa) exploran conductas que son comunes a múltiples trastornos de los dos primeros ejes diagnósticos. En concreto, el estudio conjunto con el MCMI-II muestra una convergencia en la detección de muchos de los trastornos de la persona- 
lidad y de casi todos los síndromes del Eje I, cuando era esperable una capacidad discriminativa del ASRS en la medida en que se postula como un instrumento útil para la detección del TDAH en el adulto. De modo que 13 de los 18 ítems del ASRS v.1.1. parecen explorar conductas comunes a múltiples condiciones psicopatológicas dentro de una dimensión continua entre la compulsividad (con correlación negativa) y la impulsividad (con correlación positiva). Por otra parte, si consideramos los resultados obtenidos a partir del ASRS v.1.1. en relación a los criterios explicitados por el DSM-IV-TR para el diagnóstico de TDAH en el adulto, nuestros datos no apoyan la pretendida prevalencia elevada de TDAH en población adicta en tratamiento, que en nuestra muestra alcanza un 8,2\%. La discrepancia con otros estudios se sustenta en la interpretación parcial que suele hacerse de los criterios DSM, de modo que el uso aislado de cuestionarios que incluyen criterios no especificados en el DSM (p.e., la WURS), o la confusión en el uso de escalas que exploran "rasgos" y que son interpretados como "síntomas" (p.e., la escala de impulsividad de Barrat), o la atención selectiva y exclusiva al criterio A del DSM sin explorar las condiciones que exigen los criterios B, C, D y E (p.e., explorando los síntomas de inatención, hiperactividad e impulsividad, sin una evaluación conjunta del resto de patología en el Eje I y en el Eje II) incrementan artefactualmente la prevalencia del TDAH que se pretende estudiar. Además, las características de la muestra, que en nuestro estudio se centra en sujetos que inician tratamiento en un centro específico de primer nivel por consumo de sustancias diversas, condicionan la prevalencia que pueda obtenerse. Se requieren estudios con criterios más rigurosos sobre muestras amplias, huyendo de las muestras de conveniencia (sea ésta la que sea), no concentradas en recursos hospitalarios o residenciales, y sin selección previa, para alcanzar una estimación fiable de la prevalencia real del TDAH en población adicta que busca tratamiento.

\section{REFERENCIAS}

APA, American Psychiatric Association. (2002). DSM-IV-TR. Manual diagnóstico y estadístico de los trastornos mentales. Texto revisado. Barcelona: Masson.

Artigas J., García, K. y Rigau, E. (2003). Comorbilidad en el TDAH. // Congreso Internacional de Neuropsicología en Internet. Disponible en URL [consultado 10/01/2007]: http://www.serviciodc.com/congreso/congress/pass/ conferences/Artigas1.pdf

Biederman, J., Faraone, S. V., Mick, E., Spencer, T., Wilens, T., Kiely, K., Guite, J., Ablon, J. S., Reed, E. y Warburton, R. (1995). High risk for attention deficit hyperactivity disorder among children of parents with childhood onset of the disorder: a pilot study. American Journal of Psychiatry, 152, 431-435.

Biederman, J., Faraone, S. V., Monuteaux, M. C., Bober, M.y Cadogen, E. (2004). Gender effects on attention-deficit/ hyperactivity disorder in adults, revisited. Biological Psychiatry, 55, 692-700.

Biederman, J, Wilens, T., Mick, E., Spencer, T. y Faraone, S. V. (1999). Pharmacology of attention-deficit/hyperactivity disorder reduces risk for substance use disorder. Pediatrics, 104, 1-5.

Blázquez, G., Joseph, D., Burón, E., Carrillo, C., Joseph, M., Cuyàs, M. y Freile, R. (2005). Resultados del cribado de la sintomatología del trastorno por déficit de atención con o sin hiperactividad en el ámbito escolar mediante la escala EDAH. Revista de Neurología, 41, 586-590.

Cardo, E. y Servera-Barceló, M. (2005). Prevalencia del trastorno de déficit de atención e hiperactividad. Revista de Neurología, 40 (Supl 1), S11-S15.

Cardo, E., Servera, M. y Llobera, J. (2007). Estimación de la prevalencia del trastorno por déficit de atención e hiperactividad en población normal de la isla de Mallorca. Revista de Neurología, 44, 10-14.

Comings, D. E., Chen, T. J. H., Blum, K., Mengucci, J. F. Blum, S. H. y Meshkin, B. (2005). Neurogenetic interactions and aberrant behavioral co-morbidity of attention deficit hyperactivity disorder (ADHD): dispelling myths. Theoretical Biology and Medical Modelling, 2: 50. Publicación online. Disponible en URL [consultado 19/06/2006]: http://www.tbiomed. com/content/2/1/50.

Davids, E. y Gastpar, M. (2003). Attention-deficit/hyperactivity disorder and substance abuse. Psychiatrische Praxis, 30, 182-186.

DuPaul, G. J., Power, T. J., Anastopoulos, A. D. y Reid, R. (1998). ADHD Rating Scale-IV: Checklists, Norms, and Clinical Interpretation. Nueva York: Guilford Press.

Eakin, L., Minde, K., Hechtman, L., Ochs, E., Krane, E., Bouffard, R., Greenfield, B., Looper, K. (2004). The marital and family functioning of adults with ADHD and their spouses. Journal of Attentional Disorders, 8, 1-10.

Etchepareborda. M. C. (2002). Modelos de intervención farmacológica en el trastorno por déficit de atención e hiperactividad. Revista de Neurología, 34 (Supl 1), S98-S106.

Faraone, S. V. y Biederman, J. (2005). Adult ADHD NOS: Is it a valid disorder? Program and abstracts of the American Psychiatric Association 2005 Annual Meeting; May 21-26, Atlanta, Georgia. Poster NR 459.

Faraone, S. V., Biederman, J., Doyle, A., Murray, K., Petty, C., Adamson, J. J. y Seidman, L. (2006). Neuropsychological studies of late onset and subthreshold diagnoses of adult attention-deficit/hyperactivity disorder. Biological Psychiatry, 60, 1081-1087.

Faraone, S. V., Biederman, J., Spencer, T., Mick, E., Murray, K., Petty, C., Adamson, J. J. y Monuteaux, M. C. (2006). Diagnosing adult attention deficit hyperactivity disorder: are late onset and subthreshold diagnoses valid? American Journal of Psychiatry, 163, 1720-1729. 
Faraone, S. V., Biederman, J., Spencer, T., Wilens, T., Seidman, L. J., Mick, E., Doyle, A. E. (2000). Attention deficit/hyperactivity disorder in adults: an overview. Biological Psychiatry, 48, 9-20.

Goodman. R. y Stevenson J. (1989). A twin study of hiperactivity: II. The aetiologic role of genes, family relationships, and perinatal adversity. Journal of Child Psychology and Psychiatry, 30, 691-709.

Goossensen, M. A., van de Glind, G., Carpentier, P. J., Wijsen, R. M., van Duin, D. y Kooij, J. J. (2006). An intervention program for ADHD in patients with substance use disorders: preliminary results of a field trial. Journal of Substance Abuse Treatment, 30, 253-259.

Hollander, E. y Wong, C. M. (1995). Body dysmorphic disorder, pathological gambling and sexual compulsions. Journal of Clinical Psychiatry, 56, (Supl.4), S7-S12.

Inda, M., Lemos, S., Paíno, M., Besteiro, J. L., Alonso, J. L., Bobes, J. y García, E. (2006). Dimensiones de los trastornos de la personalidad y correlatos neurofisiológicos. Actas Españolas de Psiquiatría, 34, 175-184.

Kessler, R. C., Adler, L., Ames, M., Barkley, R. A., Birnbaum, H., Greenberg, P, Johnston, J. A., Spencer, T. y Ustun, T. B. (2005). The Prevalence and Effects of Adult Attention Deficit/Hyperactivity Disorder on Work Performance in a Nationally Representative Sample of Workers. Journal of Occupational \& Environmental Medicine, 47, 565-572.

Kessler, R. C., Adler, L., Ames, M., Demler, O., Faraone, S., Hiripi, E., Howes, M. J., Jin, R., Secnik, K., Spencer, T., Ustun, T. B., Walters, E. E. et al. (2005b). The World Health Organization adult ADHD self-report scale (ASRS): a short screening scale for use in the general population. Psychological Medicine, 35, 245-256.

Kessler, R. C., Adler, L., Barkley, R., Biederman, J., Conners, C. K., Delmer, O., Faraone, S., Greenhill, L. L., Howes, M. J., Secnik, K., Spencer, T., Ustun, T. B., Walters, E. E. y Zaslavsky, A. M. (2006). The Prevalence and Correlates of Adult ADHD in the United States: Results From the National Comorbidity Survey Replication. American Journal of Psychiatry, 163, 716-723.

Levin, F. R., Evans, S. M., Brooks, D. J., Kalbag, A. S., Garawi, F. y Nunes E. V. (2006). Treatment of methadonemaintained patients with adult ADHD: double-blind comparison of methylphenidate, bupropion and placebo. Drug \& Alcohol Dependence, 81, 137-148.

Lopera, F., Palacio, L. G., Jiménez, I., Villegas, P., Puerta, I. C., Pineda, D., Jiménez, M. y Arcos-Burgos, M. (1998). Discriminación de factores genéticos en el déficit de atención (DDA). Conferencia en el I Congreso Virtual Iberoamericano de Neurología. Disponible en URL [Consultado 17/06/2006]: http://neurologia.rediris.es/ congreso-1/conferencias/neurogenetica-2.html.

McElroy, S. L., Hudson, J. I., Phillips, K. A., Keck, P. E. y Pope, H. G. (1993). Clinical and theoretical implications of a possible link between obsessive-compulsive and impulse control disorders. Depresión, 1, 121-132.
Millon T. (1999). MCMI-II. Inventario clínico multiaxial de Millon-II. Manual. Adaptación española de Ávila-Espada, A. (dir.) y Jiménez Gómez, F. (coord.) Madrid: TEA.

Millon, T. y Davis, R. D. (1998). Trastorno de la personalidad por evitación: el patrón de repliegue. En Millon, T. y Davis, R.D., Trastornos de la personalidad: más allá del DSM-IV (pp. 265-265-300). Barcelona: Masson.

Modestin, J., Matutat, B. y Würmle, O. (2001). Antecedents of opioid dependence and personality disorder: attention-deficit/hyperactivity disorder and conduct disorder. European Archives of Psychiatry and Clinical Neurosciences, 251, 42-47.

New York University (2005). Adult ADHD: Issues and Answers. NYU School of Medicine Adult ADHD Newsletter. Disponible en URL [Consultado 17/06/2006] http://www.med.nyu.edu/psych/assets/ adult_adhd_1_1.pdf.

Pappas, D. (2006). ADHD Rating Scale-IV: Checklists, Norms, and Clinical Interpretation. Journal of Psychoeducational Assessment, 24, 172-178.

Pedrero, E. J., López-Durán, A, y Olivar, Á. (2006). El trastorno negativista de la personalidad y su relación con el abuso de sustancias. Trastornos Adictivos, 8, 22-41.

Pedrero, E. J. y Puerta, C. (2006). Screening de TDAH en pacientes en tratamiento por abuso/dependencia de sustancias, utilizando el ASRS v1.1. Adicciones, Supl.1, S195-S196.

Pedrero, E. J., Puerta, C., Olivar, Á, Lagares, A. y PérezLópez, M. (2004). Trastorno por déficit de atención e hiperactividad y su relación con rasgos y trastornos de personalidad en consumidores de drogas en tratamiento: estudio del WURS y su relación con el BFQ y el MCMI-II. Una visión crítica. Trastornos Adictivos, 6, 192-212.

Ponce, G., Rodríguez, R., Pérez, J. A., Monasor, R., Rubio, G., Jiménez, M. A. et al. (2000). Trastorno por déficit de atención e hiperactividad y vulnerabilidad al desarrollo de alcoholismo: empleo de la Wender-Utah Rating Scale (WURS) para el diagnóstico retrospectivo de TDAH en la infancia de pacientes alcohólicos. Actas Españolas de Psiquiatría, 28, 357-366.

Reuter, M., Kirsch, P. y Hennig, J. (2005). Inferring candidate genes for Attention Deficit Hyperactivity Disorder (ADHD) assessed by the World Health Organization Adult ADHD Self-Report Scale (ASRS). Journal of Neural Transmission, Jan 2006, DOI 10.1007/ s00702-005-0366-5, URL: http://dx.doi.org/10.1007/ s00702-005-0366-5.

Rodríguez, R., Ponce, G., Monasor, R., Jiménez, M., Pérez, J. A., Rubio, G. et al. (2001) Validación en población española adulta de la Wender Utah Rating Scale para la evaluación retrospectiva de trastorno por déficit de atención e hiperactividad en la infancia. Revista de Neurología, 33, 138-144.

Rohde, L. A., Biederman, J., Zimmermann, H., Schmilz, M., Martins, S., Tramontina, S. (2000). Exploring ADHD age- 
of-onset criterion in Brazilian adolescents. European Child and Adolescent Psychiatry, 9, 212-218.

Schubiner, H. (2005). Substance abuse in patients with attention-deficit hyperactivity disorder : therapeutic implications. CNS Drugs, 19, 643-655.

Secnik, K., Swensen, A. Lage, M. J. (2005). Comorbidities and costs of adult patients diagnosed with attentiondeficit hyperactivity disorder. Pharmacoeconomics, 23, 93-102.

Servera, M. y Galván, M. R. (2001). Problemas de impulsividad e inatención en el niño. Madrid: Ministerio de Educación, Cultura y Deporte. Secretaría General de Educación y Formación Profesional, Centro de Investigación y Documentación Educativa (C.I.D.E.).

Spencer, T., Biederman, J., Wilens, T., Doyle, R., Surman, C., Prince, J., Mick, E., Aleardi, M., Herzig, K. y Faraone, S. (2005). A large, double- blind, randomized clinical trial of methylphenidate in the treatment of adults with attention-deficit/hyperactivity disorder. Biological Psychiatry, 57, 456-463.

Slatkoff, J. y Greenfield, B. (2006). Pharmacological treatment of attention-deficit/hyperactivity disorder in adults. Expert Opinion on Investigational Drugs, 15, 649-667.

Swanson, J. M., Sunohara, G. A., Kennedy, J. L., Regino, R., Fineberg, E., Wigal, T., Lerner, M., Williams, L., LaHoste, G. J. y Wigal, S. (1998). Association of the dopamine receptor D4 (DRD4) gene with a refined phenotype of attention deficit hyperactivity disorder (ADHD): a familybased approach. Molecular Psychiatry, 3, 38-41.
Vasterling, J. J., Duke, L. M., Brailey, K., Constans, J. I., Allain, A. N. y Sutker, P. B. (2002). Attention, learning, and memory performances and intellectual resources in Vietnam veterans: PTSD and no disorder comparisons. Neuropsychology, 16, 5-14.

Velásquez-Tirado, J. D. y Peña J. A. (2005). Evidencia actual sobre la atomoxetina. Alternativa terapéutica para el trastorno por déficit de atención e hiperactividad. Revista de Neurología, 41, 493-500.

Weisler, R. H. (2004). Adult Attention Deficit Hyperactivity Disorder. Child \& Adolescent Psychopharmacology News, 9, 1-7.

Ward, M. F., Wender, P. H. y Reimherr, F. W. (1993). The Wender Utah Rating Scale: an aid in the retrospective diagnosis of childhood attention deficit hyperactivity disorder. American Journal of Psychyatry, 150, 885-890.

Wender, P. H. (1995). Attention-Deficit Hyperactivity Disorder in adults. Nueva York, Oxford University Press.

Wender, P. H., Wolf, L. E. y Wasserstein, J. (2001). Adults with ADHD. An overview. Annals of the New York Academy of Sciences, 931, 1-16.

Wohl, M., Purper-Ouakil, D., Mouren, M. C., Ades, J. y Gorwood, P. (2005). Meta-analysis of candidate genes in attention-deficit hyperactivity disorder. Encephale, 31, 437-447.

Wilens, T. E. (2004). Impact of ADHD and its treatment on substance abuse in adults. Journal of Clinical Psychiatry, 65, 38-45.

Wilens, T., Faraone, S. V. y Biederman, J. (2004). Attentiondeficit/hyperactivity disorder in adults. JAMA, 292, 619-623. 
